\title{
Small cell carcinoma of the stomach: A report of two cases and a review of the literature
}

\author{
MARIOS BAKOGEORGOS ${ }^{1}$, DIMITRIOS KALKANIS ${ }^{2}$, PANAGIOTIS KATSAOUNIS ${ }^{3}$, VASSILIOS RAMFIDIS ${ }^{1}$, \\ CHARIKLIA SPELIADES ${ }^{4}$, EKATERINI PIERRAKOU ${ }^{4}$, SAVVAS PAPADOPOULOS ${ }^{5}$, NIKOLAOS PANTAZOPOULOS ${ }^{3}$, \\ VASSILIS GEORGOULIAS ${ }^{3}$, ATHANASIOS KOTSAKIS ${ }^{6}$ and NIKOLAOS KENTEPOZIDIS ${ }^{1}$ \\ Departments of ${ }^{1}$ Medical Oncology and ${ }^{2}$ Nuclear Medicine, 251 General Air Force Hospital, 11525 Athens; \\ ${ }^{3}$ First Department of Medical Oncology, Iaso General Hospital, 11562 Athens; ${ }^{4}$ Department of Pathology, \\ Athens Medical Center, 15125 Athens; ${ }^{5}$ Department of Pathology, Hygeia Hospital, 15123 Athens; \\ ${ }^{6}$ Department of Medical Oncology, University Hospital of Heraklion, 71110 Heraklion, Greece
}

Received March 4, 2017; Accepted October 2, 2017

DOI: $10.3892 /$ mco.2018.1624

\begin{abstract}
Primary small cell gastric carcinomas (SCGC) are rare tumors with an aggressive nature, characterized by early, widespread metastases and poor overall prognosis. SCGC shares similar clinicopathological and molecular characteristics with small cell lung carcinoma and is usually treated in a similar manner. Here, two cases of SCGC in young Caucasian male patients are presented. One patient had metastatic and the other locoregional disease. Multimodal treatment was applied in each case; the resulting survival time was 20.2 months in the patient with initially locoregional disease whereas the remains alive and disease-free 20 months after initial diagnosis. A review of the literature is also presented.
\end{abstract}

\section{Introduction}

Neuroendocrine gastrointestinal tumors constitute a heterogeneous group of tumors and share a common phenotype, with positive immunostaining for the neuroendocrine markers chromogranin A and synaptophysin, among others. Neuron-specific enolase and CD56 are often, but not always, positive (1). Pure small cell carcinomas of the gastrointestinal tract are in fact poorly differentiated, high-grade gastro-enteropancreatic neuroendocrine carcinomas (2). Primary small cell gastric carcinomas (SCGC) account for $15-20 \%$ of all gastric neuroendocrine tumors (3), $0.1 \%$ of extra-pulmonary small cell carcinomas (ESCC) and $<0.1 \%$ of all gastric cancer cases $(4,5)$, and occur primarily in males (5.4:1 ratio) (6).

Correspondence to: $\mathrm{Dr}$ Marios Bakogeorgos, Department of Medical Oncology, 251 General Air Force Hospital, 3 P. Kanellopoulou Street, 11525 Athens, Greece

E-mail: mbakogiorgos@med.uoa.gr

Key words: small cell gastric carcinomas, metastatic disease, locoregional disease
Small cell carcinoma of the gastrointestinal tract was first described in 1952 (7), and primary SCGC was initially reported in 1976 (6). Since then, only a few hundred cases of SCGC have been reported, mainly in Asian populations (6,8-10). SCGC is characterized by early, widespread metastases and a poor overall prognosis (11). Due to the rarity of the disease, and therefore the inability to conduct prospective and randomized clinical trials, clear and thorough guidelines for SCGC treatment have not yet been established. Nevertheless, the similarities between SCGC and small cell lung carcinoma (SCLC) with respect to their histopathology, molecular biology and clinical course have resulted in the use of the same therapeutic strategies for SCGC and SCLC $(6,11)$.

Herein, two cases of primary SCGC in young Caucasian males are presented, along with a review of the literature. Informed consent was obtained from both patients for whom identifying information is included in this article.

\section{Case reports}

Case 1. In December 2014, a 44-year old male patient was admitted to the 251 General Air Force Hospital in Athens (Greece), after a 2-month history of intermittent and persistent epigastric pain. The patient was afebrile with stable vital signs, no reported weight loss and the clinical examination revealed nothing else of note. The medical history was insignificant and the results of the laboratory tests were within the normal range, including the tumor biomarkers carcinoembryonic antigen (CEA), cancer antigen (CA) 19-9 and $\alpha$-fetoprotein ( $\alpha$-FP).

Esophagogastroduodenoscopy revealed a large fungating mass in the gastro-esophageal junction extending from the cardia of the stomach. The biopsy revealed a high-grade small cell carcinoma, without evidence of Helicobacter pylori gastritis (Fig. 1A). Immunohistochemistry (IHC) revealed that the tumor cells were positive for synaptophysin, chromogranin, cytokeratin 8 and 18, AE3 and CD117, and negative for CD56, cytokeratin 7 and 20 and CEA, whereas almost all cells (95-100\%) were Ki-67 positive (Fig. 1B and C).

Computed tomography (CT) of the thorax was negative, but a CT scan of the abdomen and pelvis revealed a round 

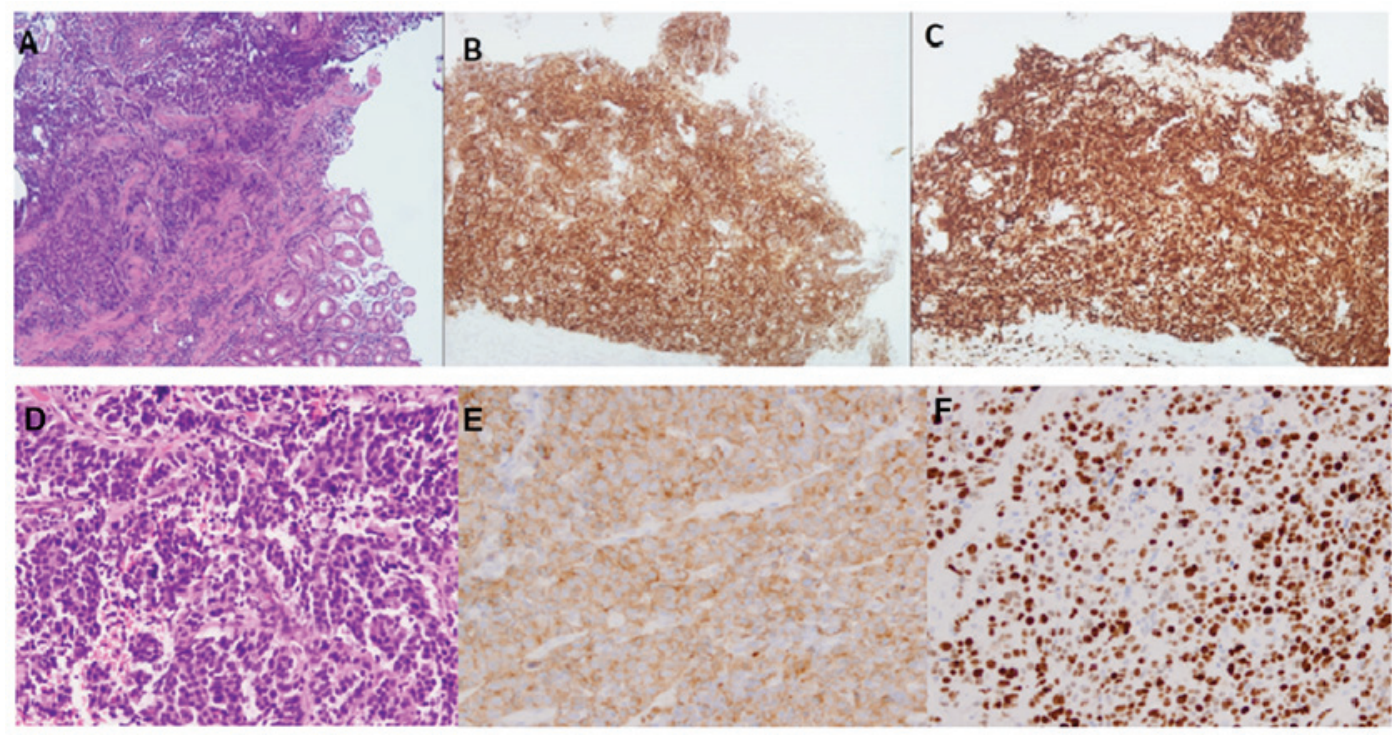

Figure 1. Case 1: (A) Hematoxylin and eosin staining, magnification x40; (B) synaptophysin (x10); (C) Ki-67 staining. Case 2: Histological appearance of the gastric small cell carcinoma. (D) Hematoxylin and eosin staining, magnification x20; the tumor cells were also positive for (E) synaptophysin (x20) and (F) almost universally for Ki-67 (x20).
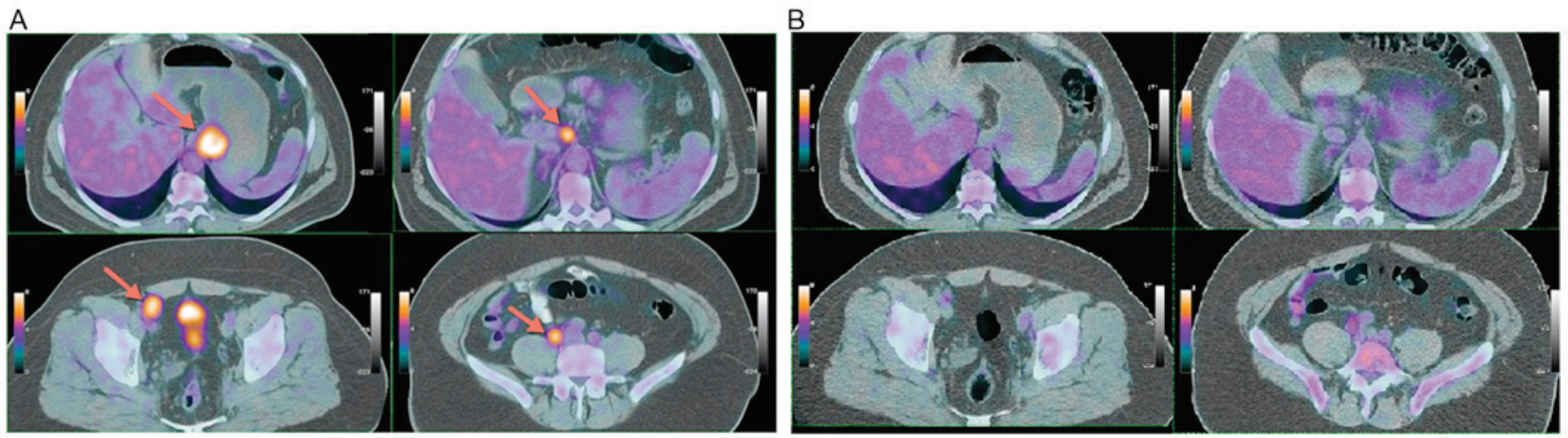

Figure 2. (A) Case 1: PET/CT at diagnosis revealing the primary tumor, one hypermetabolic paraortic and pelvic (right ileac and inguinal) lymph nodes. (B). Case 1: PET/CT scan following two chemotherapy cycles. Corresponding slices to the findings presented in (A). PET/CT, positron emission tomography/computed tomography.

$18 \mathrm{~mm}$ lesion at the gastro-esophageal junction with regional thickening of the gastric wall around the cardia of the stomach. Two enlarged lymph nodes were also identified at the right groin and at the upper third of the right external iliac chain, measuring 25 and $15 \mathrm{~mm}$, respectively.

Positron emission tomography (PET)/CT revealed increased fludeoxyglucose (FDG) uptake along the gastro-esophageal junction and cardia of the stomach [maximum standardized uptake value $\left.\left(\mathrm{SUV}_{\max }\right), 10.4\right]$, at one paraaortic lymph node (14 mm with $\mathrm{SUV}_{\max }, 10.2$ ) and at multiple pelvic (right ileac and inguinal) lymph nodes (Fig. 2A). Furthermore, a highly hypermetabolic $\left(\mathrm{SUV}_{\max }, 24.2\right)$ nodule of $29 \mathrm{~mm}$ was detected at the right thyroid lobe, and fine needle aspiration revealed a papillary thyroid cancer.

The Multidisciplinary Team (MDT) of the Institution (251 General Air Force Hospital) proposed systemic chemotherapy with standard etoposide/cisplatin combination. The patient received six cycles of chemotherapy with cisplatin $70 \mathrm{mg} / \mathrm{m}^{2}$ on day 1 and etoposide $100 \mathrm{mg} / \mathrm{m}^{2}$ on days 1,2 and 3 , every 3 weeks, with excellent tolerance for 4 months (from
December 2014 until April 2015). After the second chemotherapy cycle, a control PET/CT scan revealed a significant metabolic partial response (Fig. 2B) with only the two residual right external ileac lymph nodes (one of $12 \mathrm{~mm}$ in diameter, with $\mathrm{SUV}_{\max }, 5.5$; one of $9 \mathrm{~mm}$ in diameter, with $\left.\mathrm{SUV}_{\max }, 2.2\right)$. One month following treatment completion, imaging studies with whole body CT scans indicated a complete clinical response. Further treatment with external radiotherapy was selected due to better local disease control. The patient received 5,040 cGy in 28 fractions of $180 \mathrm{cGy}$ to the gastro-esophageal junction region, to the celiac, paraaortic, common ileac, internal ileac, external ileac and inguinal lymph node regions. Radiation was administered using intensity-modulated radiation therapy with concurrent cisplatin $\left(40 \mathrm{mg} / \mathrm{m}^{2}\right)$ every 7 days for 3 weeks.

Approximately two months following the completion of radiotherapy, the patient was underwent a total thyroidectomy for papillary thyroid cancer and received post-operative radioiodine therapy. A total of 20 months following treatment completion, the patient remains in complete remission and asymptomatic; an esophagogastroduodenoscopy with blind 
biopsies, as well as imaging studies that included a whole body PET/CT scan, did not reveal any residual disease.

Case 2. In October 2013, a 45-year old male was admitted to the Iaso General Hospital in Athens, with a 3-week history of dysphagia and pain in the upper abdomen. The patient was afebrile and asymptomatic between meals. Clinical examination was normal and the results of laboratory tests, including CEA, CA 19-9 and $\alpha-F P$, were within the normal range. Upper gastrointestinal endoscopy revealed an ulcerative tumor in the gastro-esophageal junction. The histological report indicated a high-grade small cell carcinoma positive for synaptophysin and CD56, but negative for chromogranin (Fig. 1D). Furthermore, the cells were CK7(+), CK18(+), CK20(-) and Ki-67(+) (80-90\% of the cells) (Fig. 1E and F).

Thoracic and abdominal CT scans were negative for metastatic disease, and a radical gastrectomy with D2 lymph node dissection was performed. Pathological examination of the surgical specimen confirmed the diagnosis of a small cell carcinoma with metastatic involvement in six lymph nodes of the lesser omentum, in one of the left gastric artery and in one of the hepatic artery. The tumor invaded the muscularis propria but did not penetrate the serosa. Thus, the TNM classification was T2N1M0 according to the European Neuroendocrine Tumor Society (12), and T2N3M0 stage IIIA according to the American Joint Committee on Cancer (AJCC) (12).

At 2 months following surgery, the patient was referred to the 1st Department of Medical Oncology and received 6 cycles of chemotherapy with etoposide $\left(100 \mathrm{mg} / \mathrm{m}^{2}\right.$ on days 1,2 and 3$)$ and cisplatin $\left(60 \mathrm{mg} / \mathrm{m}^{2}\right.$ on day 1$)$ every 3 weeks, for 4 months and without any treatment modifications. During the last cycle of chemotherapy, the patient experienced an acute thoracic pain; a subsequent CT scan and MRI of the mediastinum revealed a mass measuring $3.4 \times 2.5 \mathrm{~cm}$ at the lower left posterior mediastinum. An endoscopic ultrasound (EUS) confirmed this finding and a whole body PET/CT scan indicated increased FDG uptake along the mediastinal lesion $\left(\mathrm{SUV}_{\max }, 8\right)$ without other hypermetabolic localization.

Based on these findings, a metastasectomy was attempted, but the patient only underwent subtotal surgical resection of the mediastinal lesion as the mass had infiltrated the adjacent thoracic aorta. External image guided radiation therapy (5,580 cGy in 28 fractions) with concurrent carboplatin $(\mathrm{AUC}=2)$ every week for 5 weeks was subsequently administered, resulting in disease stabilization. A total of 3 months later, thoracic and abdominal CT scans revealed massive disease progression with multiple lung and liver metastases and subcutaneous nodules. A further 2 cycles of weekly paclitaxel $\left(100 \mathrm{mg} / \mathrm{m}^{2}\right.$ on days 1,8 and 15 every 28 days), in combination with bevacizumab $(10 \mathrm{mg} / \mathrm{kg}$ every 15 days), were administered without success. The patient succumbed to disease almost 3 months later due to acute respiratory failure causes by a lung infection and disease progression, 20.2 months after the initial diagnosis.

\section{Discussion}

Epidemiology. Extra-pulmonary small cell carcinomas are rare types of tumors, $18.2 \%$ of which are localized in the upper gastrointestinal tract (13). SCGC accounts for 0.1-1\% of all GI malignancies (11), whereas primary SCGC represents $\sim 0.1 \%$ of all gastric cancer cases $(4,5)$. Wu et al (6) retrospectively evaluated 205 patients with SCGC from January 1999 until December 2012, all from China, and reported a predominance of SCGC in males (male to female ratio, 5.4:1) $(6,11)$.

Molecular biology and pathology. To the best of our knowledge, there are no published data regarding the molecular basis of SCGC pathogenesis and its molecular biology. However, the available data, though limited, from cases of esophageal small cell cancer, suggest a similar molecular profile for gastrointestinal and pulmonary small cell cancer, with universal high rates of proliferative activity and telomerase inactivation, p53 overexpression (65-83 and 90\% respectively) and pRb inactivation (67-95 and 90\% respectively). K-Ras mutations ( 0.17 and $0 \%$ respectively) are rare and the loss of p16 expression (33 and 10\% respectively) is infrequent (11). The Ki67 (MIB-1) index in SCGC is, by definition, $>20 \%$, ranging from $30-95.5 \%$ (14). The pathological characteristics and the immunohistochemical features of SCGC are essentially identical to those of SCLC $(4,6,11,15-21)$. However, almost half of SCGC cases are 'mixed' or 'combined' tumors, comprised of SCC and nonSCC components $(6,11,22,23)$.

Staging and prognosis. In 2007, the European Neuroendocrine Tumour Society (ENETS) proposed a staging system of gastrointestinal neuroendocrine neoplasms, adapted for the several primary sites: i) Stomach; ii) duodenum, ampulla of Vater, proximal jejunum; iii) lower jejunum; ileum; iv) pancreas; and v) colon and rectum. It takes into account the following: i) Depth of invasion; ii) tumor size; and iii) the presence of regional lymph nodes or distant metastases $(14,24)$. This staging system was later endorsed and modified by the AJCC (12).

Patient survival depends on the treatment approach selected. Patients who received curative surgery experienced an $\sim 6$-fold increase in survival compared with those who did not (46.45 and 7.65 months respectively) $(25,26)$; in addition, patients who received post-operative chemotherapy survived $\geq 2 \mathrm{x}$ longer $(48.50$ vs. 19.00 months) (27). The median overall survival time for patients with SCGC is 18.50 months (6), with 1-, 2- and 5-year survival rates of $66.75,37.13$ and $20.10 \%$, respectively (25-29).

Treatment. Wu et al (6) reported that $97.6 \%$ (200) of the 205 studied Chinese patients with SCGC underwent surgical resection, leading to a median overall survival time of 46.45 months (range, 10.00-63.00 months). Although patients who received adjuvant chemotherapy obtained a relatively prolonged survival time; thus, curative surgery can be regarded as a standard treatment for locoregional non-metastatic SCGC $(6,27)$.

Post-operative chemotherapy is considered a standard treatment and several regimens are in clinical use (Table I) (11); however, platinum based chemotherapy forms the backbone of treatment for early and metastatic disease (30). Huang et al (27) demonstrated a survival advantage of almost 30 months for surgery plus chemotherapy (48.5 months) vs. surgery alone (19 months) (27). Pre-operative chemotherapy with the same regimen is also a rational option $(11,31)$. Cisplatin plus irinotecan is an alternative first line treatment (32), but there is no standard regimen for second line therapy. Brain metastases are infrequent and prophylactic cranial irradiation is not recommended (33).

Although concurrent or sequential chemoradiotherapy is associated with satisfactory results in patients with gastrointestinal small cell carcinoma, particularly esophageal-SCC, data regarding the effect of radiotherapy on SCGC are currently 


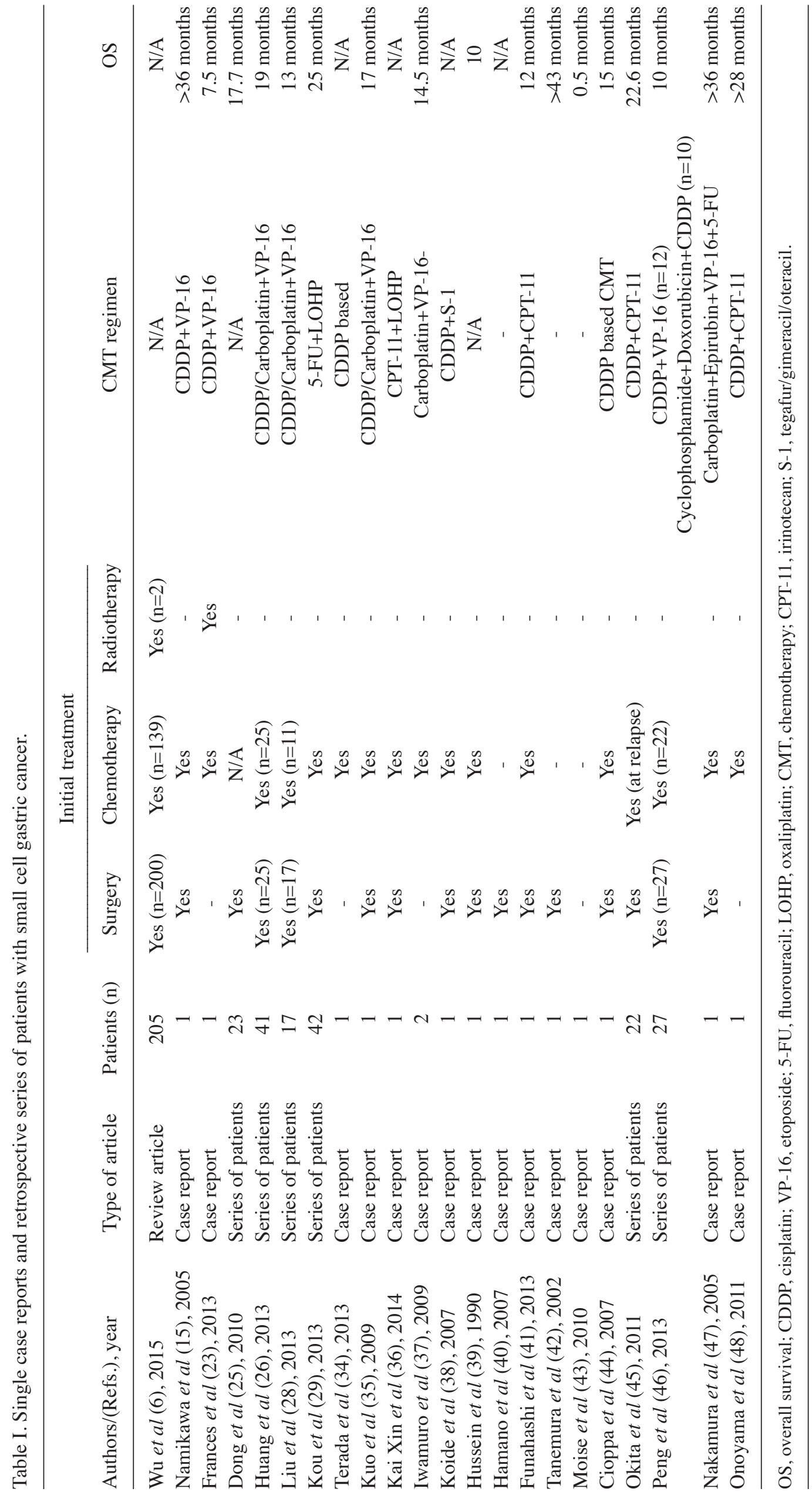


limited. In the larger published series of patients with SCGC by Wu et al (6) only two patients received radiotherapy.

The two patient cases presented herein have been treated according to current practice but had opposing outcomes. The patient with disseminated disease at diagnosis (case 1) was evaluated in the MDT and it was decided to administer first-line chemotherapy with the standard etoposide/cisplatin regimen. Chemotherapy resulted in a major objective response that was followed by radiotherapy. It is considered, as in the case of SCLC, that involved-field radiation may further disease control, thus explaining the favorable clinical outcome of the patient. Conversely, the second patient did not have the opportunity to be discussed in the MDT and underwent a 'curative' gastrectomy for locoregional disease with post-operative chemotherapy applied after a 2-month delay. However, it should be noted that the pre-surgical staging of the disease was inadequate as there was no more detailed evaluation of the regional lymph nodes status by either a PET/CT scan or a laparoscopy and lymph node sampling. Such an evaluation could change the therapeutic plan administering first systemic chemotherapy followed by, depending on the results, either curative surgery or involved-field radiotherapy. On the other hand, it cannot be excluded that the 2-month delay in the administration of chemotherapy was an important adverse contributor to the patient's clinical outcome and the early disease dissemination based on the assumption of the possible presence of occult metastatic disease at the time of initial diagnosis.

To conclude, primary SCGC is a rare type of disease in Caucasians, and the two cases discussed indicate the treatment challenges presented by this disease. SCGC is aggressive with poor prognosis and currently small retrospective case series are the main source of data for this malignancy, which shares the same histopathological, molecular, clinical and treatment characteristics with SCLC. Careful evaluation of each patient's case by the MDT and a multimodal therapeutic approach are strongly recommended for this disease, with platinum-based chemotherapy regimens to represent the standard of care. The MDT must determine for each individual case the optimal therapeutic strategy, and critically evaluate the role and the sequence of local treatments (surgery or radiotherapy) administered alone or in combination with chemotherapy. This is particularly important considering the absence of prospective randomized studies as the only data currently available are from treated patients.

\section{Acknowledgements}

The authors would like to thank Mrs. Vasso Athanasaki, Scientific Secretary of the Hellenic Oncology Research Group, for her attentive editing of this manuscript.

\section{References}

1. Öberg K, Knigge U, Kwekkeboom D and Perren A; ESMO Guidelines Working Group: Neuroendocrine gastro-enteropancreatic tumors: ESMO Clinical Practice Guidelines for diagnosis, treatment and follow-up. Ann Oncol 23 Suppl 7: vii124-130, 2012.

2. Basturk O, Tang L, Hruban RH, Adsay V, Yang Z, Krasinskas AM, Vakiani E, La Rosa S, Jang KT, Frankel WL, et al: Poorly differentiated neuroendocrine carcinomas of the pancreas: A clinicopathologic analysis of 44 cases. Am J Surg Pathol 38: 437-447, 2014.
3. Hassan MM, Phan A, Li D, Dagohoy CG, Leary C and Yao JC: Risk factors associated with neuroendocrine tumors: A U.S.-based case-control study. Int J Cancer 123: 867-873, 2008.

4. Kusayanagi S, Konishi K, Miyasaka N, Sasaki K, Kurahashi T, Kaneko K, Akita Y, Yoshikawa N, Kusano M, Yamochi T, et al: Primary small cell carcinoma of the stomach. J Gastroenterol Hepatol 18: 743-747, 2003.

5. Kim KO, Lee HY, Chun SH, Shin SJ, Kim MK, Lee KH, Hyun MS Bae SH and Ryoo HM: Clinical overview of extrapulmonary small cell carcinoma. J Korean Med Sci 21: 833-837, 2006.

6. Wu QQ, Qiang WG, Wang F, Dai KJ, Xu EC, Luo JD, Li Q, Tang H, Zhou XF and Lu XJ: Management of primary gastric small cell carcinoma in China. Int J Clin Exp Med 8: 1589-1597, 2015.

7. McKeown F: Oat-cell carcinoma of the oesophagus. J Pathol Bacteriol 64: 889-891, 1952.

8. Takaku H, Oka K, Naoi Y, Santoh N, Setsu Y and Mori N: Primary advanced gastric small cell carcinoma: A case report and review of the literature. Am J Gastroenterol 94: 1402-1404, 1999.

9. Fujisawa K, Iwashita A and Ueno H: Multiple cancers of the stomach including oatcell carcinoma, an autopsy case. Ito Cho 16: 1349-1354, 1981 (In Japanese).

10. Fukuda T, Ohnishi Y, Nishimaki T, Ohtani H and Tachikawa S: Early gastric cancer of the small cell type. Am J Gastroenterol 83: 1176-1179, 1988.

11. Brenner B, Tang LH, Klimstra DS and Kelsen DP: Small-cell carcinomas of the gastrointestinal tract: A review. J Clin Oncol 22: 2730-2739, 2004

12. Edge SB and Compton CC: The American Joint Committee on Cancer: The 7th edition of the AJCC cancer staging manual and the future of TNM. Ann Surg Oncol 17: 1471-1474, 2010.

13. Gennatas S, Noble J, Stanway S, Gunapala R, Chowdhury R, Wotherspoon A, Benepal T and Popat S: Patterns of relapse in extrapulmonary small cell carcinoma: Retrospective analysis of outcomes from two cancer centres. BMJ Open 5: e006440, 2015.

14. World Health Organization: WHO Classification of Tumours of the Digestive System. Bosman FT, Carneiro F, Hruban RH and Theise ND (eds). 4th edition. IARC WHO Classification of Tumours, Lyon, p417, 2010.

15. Namikawa T, Kobayashi M, Okabayashi T, Ozaki S, Nakamura S, Yamashita K, Ueta H, Miyazaki J, Tamura S, Ohtsuki Y and Araki K: Primary gastric small cell carcinoma: Report of a case and review of the literature. Med Mol Morphol 38: 256-261, 2005.

16. Wick MR, Weatherby RP and Weiland LH: Small cell neuroendocrine carcinoma of the colon and rectum: Clinical, histologic, and ultrastructural study and immunohistochemical comparison with cloacogenic carcinoma. Hum Pathol 18: 9-21, 1987.

17. Burke AB, Shekitka KM and Sobin LH: Small cell carcinomas of the large intestine. Am J Clin Pathol 95: 315-321, 1991.

18. Ho KJ, Herrera GA, Jones JM and Alexander CB: Small cell carcinoma of the esophagus: Evidence for a unified histogenesis. Hum Pathol 15: 460-468, 1984.

19. Takubo K, Nakamura K, Sawabe M, Arai T,Esaki Y, Miyashita M, Mafune K, Tanaka Y and Sasajima K: Primary undifferentiated small cell carcinoma of the esophagus. Hum Pathol 30: 216-221, 1999.

20. Maitra A, Tascilar M, Hruban RH, Offerhaus GJ and AlboresSaavedra J: Small cell carcinoma of the gallbladder: A clinicopathologic, immunohistochemical, and molecular pathology study of 12 cases. Am J Surg Pathol 25: 595-601, 2001.

21. Sarsfield P and Anthony PP: Small cell undifferentiated ('neuroendocrine') carcinoma of the colon. Histopathology 16: 357-363, 1990.

22. Joyce EA, Kavanagh J, Sheehy N, Beddy P and O'Keeffe SA: Imaging features of extrapulmonary small cell carcinoma. Clin Radiol 68: 953-961, 2013.

23. Frances N, Zeichner SB, Francavilla M and Cusnir M: Gastric small-cell carcinoma found on esophagogastroduodenoscopy: A case report and literature review. Case Rep Oncol Med 2013: 475961, 2013.

24. Pape UF, Jann H, Müller-Nordhorn J, Bockelbrink A, Berndt U, Willich SN, Koch M, Röcken C, Rindi G and Wiedenmann B: Prognostic relevance of a novel TNM classification system for upper gastroenteropancreatic neuroendocrine tumors. Cancer 113: 256-265, 2008

25. Dong RZ, Shi YQ, Ye YW,Fu HandZhao GF: Clinicopathological and prognostic analysis of 23 poorly differentiated neuroendocrine carcinomas of the stomach. Zhonghua Wei Chang Wai Ke Za Zhi 13: 583-586, 2010 (In Chinese). 
26. Huang S, Zheng ZX, Xu Q and Yuan XH: The diagnosis, treatment and prognosis evaluation of gastric small cell carcinoma: Analysis of 41 cases. Zhonghua Wai Ke Za Zhi 51: 225-229, 2013 (In Chinese)

27. Huang J, Zhou Y, Zhao X, Zhang H, Yuan X and Wang J: Primary small cell carcinoma of the stomach: An experience of two decades (1990-2011) in a Chinese cancer institute. J Surg Oncol 106: 994-998, 2012.

28. Liu H, Xie YB, Xu Q, Zhang JW, Tian YT, Zhao DB, Wang CF Shan Y, Zhou ZX and Yuan XH: Clinical analysis of 17 cases of gastric small cell carcinoma. Zhonghua Zhong Liu Za Zhi 35: 292-294, 2013 (In Chinese).

29. Kou Y, Gao YB, Ma J, Yang K, Fu Q and Xie JG: Prognostic analysis of 42 patients with gastric neuroendocrine carcinoma. Zhonghua Wei Chang Wai Ke Za Zhi 16: 570-573, 2013 (In Chinese).

30. Sorbye H, Strosberg J, Baudin E, Klimstra DS and Yao JC: Gastroenteropancreatic high-grade neuroendocrine carcinoma Cancer 120: 2814-2823, 2014.

31. Sorbye H: Neoadjuvant chemotherapy in extra-pulmonary neuroendocrine carcinoma. Neoadjuvant Chemotherapy. Current Applications in Clinical Practice. Oliver F Bathe (ed). http://www. intechopencom/articles/show/title/neoadjuvant-chemotherapy-inpoorly-differentiated-neuroendocrine-carcinoma, 2012.

32. Yamaguchi T, Machida N, Morizane C, Kasuga A, Takahashi H, Sudo K, Nishina T, Tobimatsu K, Ishido K, Furuse J, et al: Multicenter retrospective analysis of systemic chemotherapy for advanced neuroendocrine carcinoma of the digestive system. Cancer Sci 105: 1176-1181, 2014.

33. Cicin I, Karagol H, Uzunoglu S, Uygun K, Usta U, Kocak Z, Caloglu M, Saynak M, Tokatli F and Uzal C: Extrapulmonary small-cell carcinoma compared with small-cell lung carcinoma: A retrospective single-center study. Cancer 110: 1068-1076, 2007.

34. Terada T: Primary small cell carcinoma of the stomach: a case report with an immunohistochemical and molecular genetic analysis. Int J Clin Exp Pathol 6: 524-530, 2013.

35. Kuo SC, Chao Y, Luo JC, Lee KC, Wu CW, Li AFY, Lee RC and Li CP: Primary small cell carcinoma of the stomach successfully treated with cisplatin and etoposide. J Chin Med Assoc 72: 598-602, 2009

36. Xin K, Wei J, Wang H, Guan W and Liu B: Neoadjuvant chemotherapy followed by D2 gastrectomy and esophagojejunal Roux en Y anastomosis in gastric small cell carcinoma: A case report. Oncol Lett 8: 2549-2552, 2014.

37. Iwamuro M, Tanakab S, Besshob A, Takahashi H, Ohtab T, Takadac R and Murakami I: Two cases of primary small cell carcinoma of the stomach. Acta Med Okayama 63: 293-298, 2009.

38. Koide N, Suzuki A, Saito H, Sato T, Murakami M, Ota H and Miyagawa S: Gastric small cell carcinoma successfully treated by surgery and postoperative chemotherapy consisting of cisplatin and S-1: report of a case. Surg Today 37: 989-994, 2007.
39. Hussein AM, Otrakji CL and Hussein BT: Small cell carcinoma of the stomach. Case report and review of the literature. Dig Dis Sci 35: 513-518, 1990

40. Hamano R, Hirao T, Tokuoka M, Masuzawa T, Shibata K and Kobayashi T: A case report of gastric small cell carcinoma with long survival time by adjuvant chemotherapy-reports of chemotherapy regimens for gastric small cell carcinoma. Gan To Kagaku Ryoho 34: 609-613, 2007.

41. Funahashi H, Miyai H, Wakasugi T, Ishiguro H, Matsuo Y, Kimura M and Takeyama H: Successful combination chemotherapy with irinotecan hydrochloride and cisplatin for primary gastric small cell carcinoma: report of a case. World J Surg Oncol 11: 263, 2013.

42. Ohshita H, Kanno A, Kusakabe M, Tomita E, Nishigaki Y, Sugiyama A and Yamada T: A patient with small-cell carcinoma of the stomach with long survival after percutaneous microwave coagulating therapy (PMCT) for liver metastasis. Int J Clin Oncol 7: 128-132, 2002

43. Moise D, Singh J, Dahl K, Rashid S, Prasad A, Siddiqui G, Subramani K, Mustacchia P and Rizvon K: Extrapulmonary small cell carcinoma of the stomach: a lethal entity. Case Rep Gastroenterol 4: 298-303, 2010.

44. Cioppa T, Marrelli D, Neri A, Caruso S, Pedrazzani C, Malagnino V, Pinto E and Roviello F: A case of small-cell gastric carcinoma with an adenocarcinoma component and hepatic metastases: treatment with systemic and intra-hepatic chemotherapy. Eur J Cancer Care (Engl) 16: 453-457, 2007.

45. Okita NT, Kato K, Takahari D, Hirashima Y, Nakajima TE, Matsubara J, Hamaguchi T, Yamada Y, Shimada Y, Taniguchi H and Shirao K: Neuroendocrine tumors of the stomach: chemotherapy with cisplatin plus irinotecan is effective for gastric poorly-differentiated neuroendocrine carcinoma. Gastric Cancer 14: 161-165, 2011.

46. Peng C, Shen S, Zhang X and Zou X: Limited stage small cell carcinoma of the gastrointestinal tract: a clinicopathologic and prognostic analysis of 27 cases. Rare Tumors 5: e6, 2013.

47. Nakamura Y, Otani S, Otaka M, Shimada T, Takahashi S, Saito M, Takahashi T, Komatsu M, Suzuki T, Okubo S, Hayashi M and Sasano H: Gastric small cell carcinoma with marked response to neoadjuvant chemotherapy. Int J Clin Oncol 10: 348-352, 2005.

48. Onoyama H, Iwasaki Y, Ohashi M, Iwanaga T, Ohinata R, Maeda Y, Omuro Y, Sasaki E, Shimoyama T and Tateishi Y: A case of gastric neuroendocrine cell carcinoma successfully treated by neoadjuvant chemotherapy. Gan To Kagaku Ryoho 38: 2131-2133, 2011.

This work is licensed under a Creative Commons Attribution-NonCommercial-NoDerivatives 4.0 International (CC BY-NC-ND 4.0) License. 